\title{
Evaluación de la calidad citológica a través de tres espátulas para la toma del PAP
}

\author{
CERELDA LORZA $^{(1)}$, RODRIGO PRADO BUZETA ${ }^{(2)}$ y JORGE RODRÍGUEZ ${ }^{(3)}$
}

\section{RESUMEN}

Objetivo: identificar la espátula que presente el menor porcentaje de PAP "menos que óptimos”. Metodología: estudio transversal, cuya muestra fue de carácter intencional y estratificada proporcionalmente, constituida por 761 mujeres entre 25 años y 64 años de los consultorios del Servicio de Salud Metropolitano Norte (SSMN). A cada mujer se le tomó PAP por parte de las matronas del servicio utilizando una de tres espátulas: Ayre; espátula plástica y la combinación Citobrush - Ayre $(C+A)$. Los PAP se clasificaron en "satisfactorios" o "menos que óptimos" según el Sistema Bethesda. Resultados: el mayor porcentaje de "menos que óptimas" (17,4\%), se ubicó entre los 25 a 34 años de edad, y el mínimo-0,8\%- entre los 55 a 64 años, siendo este resultado estadísticamente significativo (pvalue $<0,000$ Prueba Chi2). Al comparar la "calidad citológica" con cada una de las espátulas utilizadas se encontraron diferencias significativas (pvalue <0,014). La combinación $(C+A)$ y la espátula plástica tuvieron los menores porcentajes de "menos que óptimas" (9,8\% y 10\%, respectivamente) comparado con la espátula de Ayre (17,3\%). Conclusión: La combinación $(C+A)$ presentó el menor porcentaje de "menos que óptimos" y la mejor "calidad citológica". La combinación $(C+A)$ se comportó como un factor favorecedor de la "calidad citológica". La mejor "calidad citológica" está asociada a las mayores edades con todas las espátulas utilizadas en este estudio.

Palabras clave: calidad citológica, menos que óptimas, espátula de Ayre, espátula plástica, Citobrush.

\section{ABSTRACT \\ EVALUATION OF CYTOLOGICAL QUALITY IN THREE DIFFERENT SPATULAS FOR PAP TESTING}

Objective: Identify the spatula that achieves the lowest percentage of "less tan optimal" PAP smears. Methodology: Cross-sectional study, with an intentional and proportionally stratified simple, consisting of 761 women between 25 and 64 years of age, in the public health centers of the Northern Metropolitan Health Service. Midwives took the PAP sample from each women using one of the three spatulas: Ayre, a plastic spatula and the combination Citobrush-Ayre $(C+A)$. (Fig 1, 2, 3). The PAP samples were classified as "satisfactory" or "less tan optimal" according to the Bethesda System. Results: The highest percentage of "less tan optimal" samples, (17.4\%), was found in women between 25 and 34 years of age, and the minimum (0.8\%) in women from 55 to 64 years. This result was statistically significant ( $p$ value $\left.<0.000 \mathrm{Chi}^{2}\right)$. Comparing the "cytological quality" of each spatula, significant differences were also found ( $p$ value $<0.014$ ). The combination $(C+A)$ and the plastic spatula had lower percentages of "less than optimal" samples (9.8\% and 10\%, respectively) compared with the Ayre spatula (17.3\%).

\footnotetext{
(1) Magister en Salud Pública Kra 57 \# 13-60, Barrio 1 de Mayo, Cali-Valle. Colombia. cereldalorza@hotmail.com

(2) Ex Director Laboratorio Nacional de Referencia de Cáncer Cervicouterino. Campus Occidente. Facultad de Medicina Universidad de Chile. Santiago. Chile.

(3) Escuela de Salud Pública. Facultad de Medicina. Universidad de Chile. Santiago. Chile.
} 
Conclusion: The combination $(C+A)$ achieved the lowest percentage of "less than optimal" samples, and the best "cytological quality." The combination $(C+A)$ was a factor favoring "cytological quality." The best "cytological quality" is associated with older age groups with all spatulas used in this study.

Key words: cytological quality, less tan optimal, Ayre spatula, plastic spatula, Citobrush.

\section{INTRODUCCIÓN}

El tamizaje de cáncer uterino (Ca CU) se ha centrado en la toma del frotis de Papanicolau (PAP) en mujeres asintomáticas. Esta prueba ha demostrado ser un método eficaz de prevención secundaria. Después del advenimiento del PAP, se pudo apreciar reducciones significativas en la incidencia de esta patología a tasas de 10 casos por cada 100.000 mujeres en Canadá, Estados Unidos y otros países industrializados ${ }^{1}$. Adicionalmente la mortalidad del Ca CU puede ser reducida hasta en un $80 \%$ si la calidad del tamizaje y la cobertura es alta como ocurrió en los países nórdicos ${ }^{2}$.

El PAP consiste en obtener una muestra de células del cuello uterino: del endocervix, de la zona de tranformación y del ectocervix. Esta muestra es analizada y reportada según el Sistema Bethesda, 3, Anexo1 que define la "calidad citológica" como "satisfactoria" para la evaluación y "menos que óptimos". Los PAP "menos que óptimos" son una limitante para el tamizaje citológico, pues no cuentan con células endocervicales. Estas son la garantía de un adecuado muestreo de la Zona de Transformación que es el segmento anatómico del cuello uterino donde se inician las lesiones ${ }^{4}$. La presencia de células endocervicales en la muestra citológica depende de varios factores como: la espátula utilizada, el operador y la paciente, entre otros.

Hoy existen diversas espátulas para la toma del PAP, con grados variables para lograr PAP "satisfactorios" en contraposición con los PAP "menos que óptimos". Por ejemplo, la combinación de citobrush - espátula de Ayre $(\mathrm{C}+\mathrm{A})$ ha sido postulada como una de las mejores alternativas para el tamizaje del $\mathrm{Ca} \mathrm{CU}$ en varios estudios ${ }^{5,6,9}$.
En el sistema público de salud chileno se utiliza la espátula de Ayre, obteniéndose un porcentaje nacional de $13.45 \%$ de "menos que óptimos" al año 2005 y de $15.4 \%$ para el Servicio Metropolitano Norte (SSMN) ${ }^{7}$ La normativa del Programa de Pesquisa y Control de Cáncer-Uterino en Chile establece un tope permitido de hasta $10 \%$ de PAP "menos que óptimos"s.

Con el objetivo de identificar la espátula que presentara el menor porcentaje de "menos que óptimos" y mejorara la "calidad citológica”, el presente estudio comparó la espátula de Ayre con la espátula plástica y con la combinación citobrush-Ayre $(\mathrm{C}+\mathrm{A})$ en el SSMN.

\section{MATERIAL Y MÉTODO}

Este trabajo fue de tipo analítico, cuasi experimental y transversal. La población estuvo conformada por las pacientes entre $25 \mathrm{y}$ 64 años inscritas en el Programa de la Mujer en los consultorios de atención primaria del SSMN.

La muestra fue recolectada por las matronas/es en cinco consultorios de mayo a diciembre de 2007. Cada mujer fue tamizada con una de las espátulas y los PAP fueron analizados en el Laboratorio Nacional de Citopatología de Chile. Los resultados se recopilaron de la base de datos del laboratorio (cito-expert) y clasificados en "satisfactorios" o "menos que óptimos" según el Sistema Bethesda $(1988)^{3}$. (Ver anexo 1)

Se utilizaron tres tipos de espátulas para la toma del PAP: la espátula de Ayre, la espátula plástica y la combinación citobrush-Ayre $(\mathrm{C}+\mathrm{A})$. (Ver figuras 1,2 y 3 ) 
Figura 1. Espátula de Ayre

Figura 2. Espátula plástica

Figura 3. Citobrush

\section{Criterios de inclusión}

- Participación voluntaria mediante consentimiento informado.

- Mujeres entre 25 y 64 años.

- Mujeres que se atienden en la red pública (SSMN).

\section{Criterios de exclusión:}

- No aceptación de consentimiento informado.

- Embarazo y puerperio.

- Patología cervical previa.

- PAP insatisfactorio ( ver Anexo 1)

Se realizó un análisis con Prueba de $\mathrm{Chi}^{2}$ (pvalue < 0.05) con software estadístico SPSS 13. Para las variables que presentaron asociación significativa, se utilizaron residuos estandarizados para evaluar las celdas causantes de asociación.

La muestra de esta tesis fue obtenida de un estudio de calidad citológica emprendido por el SSMN, el Centro de Oncología, el Laboratorio Nacional de Citopatología y la Facultad de Medicina de la Universidad de Chile.

Una población total es de 133.645 mujeres entre 25 y 64 años inscritas en el Programa de Salud la Mujer del SSMN.

\section{RESULTADOS}

Edad mínima de 25 años y máxima de 64, con un promedio de 41,93 años y una desviación estándar de 10,76.
La "calidad citológica" general de este estudio fue: PAP "satisfactorios" $87,6 \% \mathrm{y}$ $12,4 \%$ de PAP "menos que óptimos". La espátula de Ayre y la combinación $(\mathrm{C}+\mathrm{A})$ se utilizaron en igual número de mujeres (255) ocupándose cada una en el 33,5\%. La espátula plástica se utilizó en 251 mujeres correspondiendo al $33 \%$.

La "calidad citológica" mejoró con cada década de edad: $17,4 \%$, "menos que óptimas" para la década de 25 a 34 años; $15,7 \%$ en la década de 35 a 44 años; 9,3\% en la década de 45 a 54 años; siendo mínima, $0,8 \%$, en la última década. Estas diferencias fueron estadísticamente significativas (pvalue $<0,000$ ).

Tabla 1. Distribución de la calidad citológica por décadas de edad para una muestra del SSMN.

\begin{tabular}{|c|c|c|c|}
\hline & \multirow[t]{2}{*}{ Porcentaje } & $\begin{array}{l}\text { Calidad } \\
\text { citológica }\end{array}$ & \multirow[t]{2}{*}{ Total } \\
\hline & & $\begin{array}{l}\text { Menos que } \\
\text { óptima }\end{array}$ & \\
\hline 25 a 34 años & $\begin{array}{l}\text { Frecuencia } \\
\% \text { edad década }\end{array}$ & $\begin{array}{r}40 \\
17,4 \%\end{array}$ & $\begin{array}{r}230 \\
100 \%\end{array}$ \\
\hline 35 a 44 años & $\begin{array}{l}\text { Frecuencia } \\
\% \text { edad década }\end{array}$ & $\begin{array}{r}36 \\
15,7 \%\end{array}$ & $\begin{array}{r}230 \\
100 \%\end{array}$ \\
\hline 45 a 54 años & $\begin{array}{l}\text { Frecuencia } \\
\% \text { edad década }\end{array}$ & $\begin{array}{r}17 \\
9,3 \%\end{array}$ & $\begin{array}{r}183 \\
100 \%\end{array}$ \\
\hline 55 a 64 años & $\begin{array}{l}\text { Frecuencia } \\
\% \text { edad década }\end{array}$ & $\begin{array}{r}1 \\
0,8 \%\end{array}$ & $\begin{array}{r}118 \\
100 \%\end{array}$ \\
\hline Total & $\begin{array}{l}\text { Frecuencia } \\
\% \text { edad década }\end{array}$ & $\begin{array}{r}94 \\
12,4 \%\end{array}$ & $\begin{array}{r}53 \\
100 \%\end{array}$ \\
\hline
\end{tabular}

Prueba $\mathrm{Chi}^{2}$

La combinación $(\mathrm{C}+\mathrm{A})$ y la espátula plástica tuvieron los menores porcentajes de "menos que óptimas" $(9,8 \%$ y $10 \%$, respectivamente) comparados con la espátula de Ayre $(17,3 \%)$, diferencia que fue significativa (pvalue $<0,014)$. 
Tabla 2. Distribución de la calidad citológica por espátula para una muestra del SSMN.

\begin{tabular}{|c|c|c|c|}
\hline \multirow{2}{*}{ Espatula } & \multirow{2}{*}{ Porcentaje } & $\begin{array}{l}\text { Calidad } \\
\text { citológica }\end{array}$ & \multirow{2}{*}{ Total } \\
\hline & & $\begin{array}{l}\text { Menos que } \\
\text { óptima }\end{array}$ & \\
\hline Ayre & $\begin{array}{l}\text { Frecuencia } \\
\% \text { espátula }\end{array}$ & $\begin{array}{r}44 \\
17,3 \% \\
\end{array}$ & $\begin{array}{r}255 \\
100,0 \% \\
\end{array}$ \\
\hline Plástica & $\begin{array}{l}\text { Frecuencia } \\
\% \text { espátula }\end{array}$ & $\begin{array}{r}25 \\
10 \%\end{array}$ & $\begin{array}{r}251 \\
100,0 \%\end{array}$ \\
\hline $\begin{array}{l}\text { Citobrush } \\
+ \text { Ayre }\end{array}$ & $\begin{array}{l}\text { Frecuencia } \\
\% \text { espátula }\end{array}$ & $\begin{array}{r}25 \\
9,8 \%\end{array}$ & $\begin{array}{r}255 \\
100,0 \%\end{array}$ \\
\hline Total & $\begin{array}{l}\text { Frecuencia } \\
\% \text { Total }\end{array}$ & $\begin{array}{r}94 \\
12,4 \%\end{array}$ & $\begin{array}{r}761 \\
100,0 \%\end{array}$ \\
\hline
\end{tabular}

*Prueba $\mathrm{Chi}^{2}$

Con respecto al diagnóstico clínico y la "calidad citológica" de las mujeres "sanas", el $87 \%$ tenía un PAP "satisfactorio" y el $13 \%$ "menos que óptimo".

De los PAP con "inflamación" el 88,7\% fueron "satisfactorios", versus $11,3 \%$ que fueron "menos que óptimos".

Los PAP con "infecciones" se distribuyeron asi: $87,5 \%$ "satisfactorios" y 12 , $5 \%$ "menos que óptimos". Las diferencias encontradas entre el "diagnóstico" y la "calidad citológica" no fueron significativas (pvalue < $0,851)$.

Tabla 3. Distribución de calidad citológica por diagnósticos para una muestra del SSMN.

\begin{tabular}{|l|l|r|r|}
\hline \multirow{2}{*}{ Diagnóstico } & \multirow{2}{*}{ Porcentaje } & $\begin{array}{l}\text { Calidad } \\
\text { Citológica }\end{array}$ & \multirow{2}{*}{ Total } \\
\cline { 3 - 4 } & & $\begin{array}{l}\text { Menos que } \\
\text { óptima }\end{array}$ & \\
\hline \multirow{2}{*}{ Sana } & $\begin{array}{l}\text { Frecuencia } \\
\text { \% diagnóstico }\end{array}$ & 57 & 437 \\
& Inflamación & $\begin{array}{l}\text { Frecuencia } \\
\text { \% Diagnóstico }\end{array}$ & $100 \%$ \\
\hline \multirow{2}{*}{ Infección } & $\begin{array}{l}\text { Frecuencia } \\
\text { \% Diagnóstico }\end{array}$ & $12,3 \%$ & $100 \%$ \\
\hline \multirow{2}{*}{ Total } & $\begin{array}{rlr}30 \\
\end{array}$ & Frecuencia & 24 \\
& $\%$ Diagnóstico & $100 \%$ \\
\hline
\end{tabular}

\section{DISCUSIÓN}

Este estudio, utilizó parte de la muestra de un estudio mayor en desarrollo, situación que determinó el diseño y el muestreo, limitando el control de sesgos desde la etapa inicial del diseño.

La aleatorización de las mujeres podría haber evitado sesgo de selección y la aleatorización de la espátula por mujer habría aportado mayor rigor al estudio. Este trabajo cumplió con el objetivo propuesto, permitiendo obtener una primera impresión de las variables estudiadas y dejar planteadas asociaciones entre las variables consideradas. Teniendo en cuenta que se trabajó con datos parciales de una investigación mayor, podrían considerarse éstos resultados como preliminares. De todas maneras es loable el esfuerzo y la coordinación del servicio de salud, y la colaboración de las matronas quienes trabajaron con nuevas espátulas $(\mathrm{C}+\mathrm{A}$ y espátula plástica) por primera vez.

Al explorar la "calidad citológica" del universo (SSMN) con respecto a la muestra, se observó una reducción de 3 puntos porcentuales en los PAP "menos que óptimos" de la muestra $-12,4 \%$ versus $15,4 \%$ en la población tota $1^{6}$, probablemente atribuible, a la introducción de nuevas espátula como la plástica y la combinación $(\mathrm{C}+\mathrm{A})$.

Respecto a la "calidad citológica" y a la "espátula" utilizada se verificó, como en otros estudios y en otros países, que la combinación $(\mathrm{C}+\mathrm{A})$ es un factor favorecedor de la "calidad citológica" al ser comparada con otras ${ }^{4,5}$. En este trabajo la combinación $(\mathrm{C}+\mathrm{A})$ resultó en un mayor porcentaje de PAP "satisfactorios" $(90,2 \%)$ en comparación con la espátula plástica $(90 \%)$ y Ayre $(82,7 \%)$, tal como se documentó en el meta análisis de Hirsch et al $(98 \%)^{6}$.

Los nuevos instrumentos mejoraron la "calidad citológica" al reducir el porcentaje de PAP "menos que óptimos" de $17,3 \%$ para la espátula de Ayre a $10 \%$ y 9,8\% para la espátula plástica y la combinación $(\mathrm{C}+\mathrm{A})$, respectivamente. Las nuevas espátulas cumplen mejor 
Anexo 1. Sistema Bethesda para el reporte de diagnósticos citológicos, 1988.

\begin{tabular}{|c|c|c|}
\hline \multicolumn{3}{|c|}{ I Calidad de la muestra / Adecuación del espécimen } \\
\hline Satisfactoria para evaluación: & Satisfactoria para evaluación pero limitada por: & Insatisfactoria para evaluación \\
\hline $\begin{array}{l}\text { Muestra satisfactoria (incluye } \\
\text { zona transformación) }\end{array}$ & $\begin{array}{l}\text { No hay componente de zona de transforma- } \\
\text { ción: } 50-75 \% \text { de las células están ocultas por: } \\
\text { sangre, inflamación áreas gruesas, mala fija- } \\
\text { ción, artefacto por desecación y contaminante. }\end{array}$ & $\begin{array}{l}\text { Células escamosas cubren } \\
\text { menos del } 10 \% \text { de la lámina. } \\
\text { Más del } 75 \% \text { de las células } \\
\text { epiteliales están ocultas por: } \\
\text { sangre, inflamación áreas } \\
\text { gruesas, mala fijación, artefac- } \\
\text { to por desecación y contami- } \\
\text { nante. }\end{array}$ \\
\hline \multicolumn{3}{|c|}{ II Categorías diagnósticas } \\
\hline \multicolumn{3}{|c|}{ Dentro de límites normales para LIE } \\
\hline \multicolumn{3}{|c|}{$\begin{array}{l}\text { Cambios celulares benignos: presencia de Tricomonas, hongos sp candida, cambios de flora bacteriana tipo vagi- } \\
\text { nosis bacteriana, bacterias actinomyces sp, cambios celulares compatibles con HPV. }\end{array}$} \\
\hline \multicolumn{3}{|c|}{ Cambios reactivo asociados con: inflamación, radiación, reparación, atrofia con inflamación, DIU, otros. } \\
\hline $\begin{array}{l}\text { Anormalidad epiteliales } \\
\text { Células escamosas } \\
\text { Células escamosas atípicas de } \\
\text { ASCUS asociado con inflama } \\
\text { ASCUS asociado a atrofia } \\
\text { ASCUS no puede excluirse A- } \\
\text { Metaplasia atípica (Dx diferen } \\
\text { Lesiones intraepiteliales escan } \\
\text { Lesiones intraepiteliales escan } \\
3 \text { con características sugestiva } \\
\text { Carcinoma de células escamos } \\
\text { Células glandulares } \\
\text { Células endometriales, citológ } \\
\text { Células glandulares atípicas de } \\
\text { Células glandulares atípicas ce } \\
\text { Células malignas con adenoca }\end{array}$ & $\begin{array}{l}\text { E } \\
1 \text { de A-LIE) } \\
\text { as de grado bajo (B-LIE) comprende: displasia } 1 \\
\text { as de grado alto (B-LIE) comprende: displasia m } \\
\text { e invasión (si se sospecha invasión). }\end{array}$ & $\begin{array}{l}\text { e/CIN } 1 \text { HPV } \\
\text { derada, severa y CIS/CIN } 2 \text { y }\end{array}$ \\
\hline
\end{tabular}

la normativa del Programa de Pesquisa y Control de Cáncer-uterino en $\mathrm{Chile}^{8}$ de un $10 \%$ de PAP "menos que óptimos", en comparación con el desempeño de la espátula de Ayre.

Hutchinson describió PAP "satisfactorio" para la espátula de Ayre de $74 \%$ (grupo control); Plástica $81 \%$ y Citobrush + Ayre $93 \%{ }^{9}$. En el estudio, la espátula plástica y la combinación $(\mathrm{C}+\mathrm{A})$ mejoraron la calidad en todos los rangos de edad, y se acentuó por encima de los 50 años, mientras que para el grupo control (Ayre) la "calidad citológica" fue inferior, específicamente de los 40 a 49 años en adelante.
En este estudio, la "calidad citológica", en las edades más jóvenes, mostró mayor porcentaje de "menos que óptimas", y a partir de los 44 años de edad mejoró la "calidad citológica", para las tres espátulas utilizadas. PAP "menos que óptimos" de 17,4\% en el grupo 25 a 34 años; $15,7 \%$ de 35 a 44 años; 9,3\% de 45 a 54 años; y $0,8 \%$ en el grupo de 55 a 64 años.

Con respecto a la inflamación e infección, que podrían interferir con la "calidad citológica" por ausencia de células endocervicales $(\mathrm{OR}=3,09$, pvalue $<0,001)$ como lo planteó un estudio estadounidense ${ }^{(5)}$ en el presente es- 
tudio no se encontró asociación. Posiblemente debido al escaso número de pacientes con inflamación o infección y PAP "menos que óptimo" no permitió verificar la asociación.

En este trabajo se identificó a la combinación $(\mathrm{C}+\mathrm{A})$ y la espátula plástica como las que presentaron la mejor "calidad citológica". Estos resultados coinciden, en gran medida, con la bibliografía existente ${ }^{4,5,10,11}$. Como hallazgo adicional se encontró que la edad se asocia con la "calidad citológica" y dicha asociación es significativa.

En conclusión, la combinación $(\mathrm{C}+\mathrm{A})$ presentó la mejor "calidad citológica" en términos del menor porcentaje de "menos que óptimos".

La edad y el instrumento son factores favorecedores de la "calidad citológica".

\section{AGRADECIMIENTOS}

A todos y cada uno de quienes nos acogieron en su aula, en su trabajo y como parte de su equipo humano.

\section{REFERENCIAS}

1. LEWIS, M (2004). Análisis de la situación del $\mathrm{CaCU}$ en América Latina y el Caribe. Washington, D.C. OPS pg: 2.

2. LAARA E, DAY NE, HAKAMA M. (1987). Trends in mortality from cervical cancer in the nordic countries: association with organised screening programmes. The Lancet. Volumen $30 \mathrm{~N}^{\circ}$ 1, pg: 1247-9.

3. INSTITUTO NACIONAL DE CÁNCER (1988). Sistema Bethesda para el reporte de diagnósticos citológicos.
4. ARIAS J, GONZÀLEZ M, SAONA P. (2001). Comparación citológica entre las técnicas de espátula de Ayre y citoescobilla (cytobrush) en la toma de muestras cervicovaginales. (En línea) Ginecología y Obstetricia. Volumen $47 \mathrm{~N}^{\circ} 3$, pg: 158-160. Fecha de acceso May $25 / 07$. Disponible http://sisbib.unmsm. edu.pe/BVRevistas/ginecologia/Vol_47N3_2001/ Compa_Cito.htm

5. MARCHAND L, MUNDT M, KLEIN G, AGARWAL SC. (2005). Optimal collection technique and devices for a quality pap smear. WMJ. javascript: AL_get (this, 'jour', 'WMJ.'). Volumen $104 \mathrm{~N}^{\circ}$ 6, pg: 51-55.

6. MARTN-HIRSCH P, JARVIS G, KITCHENER H, LILFORD R (1999). Collection devices for obtaining cervical cytology samples. The Lancet. Volumen 354, pg: $1763-70$.

7. Estadística Laboratorio Nacional de Referencia de Citopatología 2005.

8. MINISTERIO DE SALUD (1998). Orientaciones para la pesquisa y control del cáncer cérvico uterino en Chile. Ed. Santiago: Minsal, pg: 38

9. HUTCHINSON M, FERTITTA L, GOLDBAUM B, HAMZA M, VANERIAN S, ISENSTEIN L (1991). Cervex-Brush and Cytobrush. Comparison of their ability to sample abnormal cells for cervical smears. The journal of reproductive Medicine. Volumen 36 $\mathrm{N}^{\circ} 8$ pg: $581-86$.

10. GERMAIN M, HEATON R, ERICKSON D, HENRY M, NASH J, O'CONNOR D. (1994) A comparison of the three most common Papanicolaou smear collection techniques. Obstetrics \& Gynecology. Volumen 84, № 2 pg: $168-72$.

11. EISENBERG D, HERNANDEZ E, TENER T, ATKINSON B. (1997). Order of endocervical and ectocervical cytologic sampling and the quality of the papanicolaou smear. Obstetrics \& Gynecology. Volumen $90 \mathrm{~N}^{\mathrm{o}}$ 5, pg: 755-758.

Recepción : 30 de agosto de 2010 Aprobación: 16 de diciembre de 2010

Usted puede comentar éste y otros artículos publicados en la Revista Chilena de Salud Pública, enviando un correo electrónico a revistasp@med.uchile.cl 